\title{
Psychological Injury and Law: Journal Policy on Ongoing Debates
}

\author{
Gerald Young
}

Published online: 15 April 2009

(C) Springer Science + Business Media, LLC 2009

\begin{abstract}
This journal, Psychological Injury and Law, has made it a policy to publish articles that are part of ongoing debates. They might not be subject to the standard review process and are published from the perspective that the reader should decide on the merits of the science and arguments presented and that rebuttals, as well, should be allowed in order to make the best scientific case possible. In response to queries, the journal editor describes in depth the review process undertaken for Butcher et al. (Psychological Injury and Law 1(3):191-209, 2008). The journal editor indicated to the reviewers of Butcher et al. (Psychological Injury and Law 1(3):191-209, 2008), that "we let opinions stand even if we do not agree with them, checking uniquely the methodology, data, and science underlying the opinion, and let the scholar writing the rebuttal deal with any differences of opinion, also by addressing methodology, data, and science." Ben Porath et al. (Psychological Injury and Law 2(2), 2009) have written a rebuttal of Butcher et al., equally reviewed from this perspective.
\end{abstract}

Keywords Editorial policies · Ongoing debates

The article by Butcher et al. (2008) has generated much comment and requests for clarification of the review process. It has been followed by a rebuttal by Ben Porath et al. (2009), and the first author of that article had communicated with me right from the appearance of the digital version of the article in question on the publisher's website.

G. Young $(\bowtie)$

Department of Psychology, Glendon College, York University,

2275 Bayview Ave.,

Toronto, ON, Canada, M4N 3M6

e-mail: gyoung@glendon.yorku.ca
The following is taken from the opening editorial in issue 1 of PIL (Young 2008a) and indicates how the type of article in question should be subject to reviews conducive to a rebuttal format.

"A reviewer may disagree with the conclusions found in a submission, but if the paper is of the controversial type that deserves publication with a (simultaneous) rebuttal, the reviewer should propose this option instead of rejecting the paper. Reviewers will encounter scenarios such as this because the adversarial nature of the field may characterize some submissions. Should the reviewer of a particular controversial paper disagree with the conclusions reached, as long as the manuscript is based on acceptable methodology, data, and reasoning, within appropriate limits in the context of the nature of the disagreement involved in the field, the recommendation should tend towards accepting the manuscript, with proposal of an invitation for rebuttal." (pp. 4-5).

That such a policy characterizes a journal in forensic psychology should not be surprising; at least one other similar journal adheres to a similar policy on publishing articles on ongoing debates (Journal of Forensic Psychology Practice, as verified March 2, 2009).

In an editorial in 2008 (Young 2008b), I had indicated that,

"Two of the four reviewers of the Butcher et al. article queried including one part of the article. As editor in chief of the journal, I made the decision to publish the article in its entirety, and the editorial board is not considered responsible. My argument is that we had wanted both sides to present their best case - that is, both for the article in question and the promised 
rebuttal - and to let the reader decide the relative merits of the arguments made. Therefore, even though we had undertaken careful reviews in the case of these two articles, they were reviewed from the perspective of journal policy that they were part of an ongoing debate on the issue at hand, and we leave it to the reader to decide on their scholarly/scientific merits." (p. 213)

In another editorial in 2009 on the review process for this article (Young 2009), I had written that,

"In Young (2008a), I indicated that the journal would publish a rebuttal to the Butcher et al. (2008) article. In the present issue, Ben Porath et al. (2009) offer their rebuttal, and it is clear that the two sets of authors have quite different opinions on the validity of the Fake Bad Scale (FBS). PIL's journal policy in such cases is to allow both sides to present their best arguments and to let the readers decide. I served as action editor for the rebuttal, but it was accepted for publication by four psychologists, as was the original article of Butcher et al. Reviewers were aware that in the end, it is the journal readers who have to arrive at their own conclusions about the quality of the two papers and the arguments that they present for and against the FBS.” (p. 61)

Indeed, I repeated journal policy to reviewers of the Butcher et al. article.

"In my understanding of the review of contentious articles that are going to be rebutted, we let opinions stand even if we do not agree with them, checking uniquely the methodology, data, and science underlying the opinion, and let the scholar writing the rebuttal deal with any differences of opinion, also by addressing methodology, data, and science."

With this backdrop, I address the two major concerns that have arisen about the review process for the Butcher et al. paper.

\section{Concerns Expressed About the Review Process for the Butcher et al. (2008) PIL Article}

1. The Butcher et al. paper published in PIL was not subjected to the normal peer-review process. If it was published as part of an ongoing debate, the article should have been published with a disclaimer by the editor or their designee to which they put forth the exception to the peer-review status for the article(s) and state why.

2. The paper included anonymous excerpts of letters sent to a test publisher, and so the reviewers expected confiden- tiality, yet the anonymous excerpts appeared in this article. What is the propriety of doing so in a scientific journal?

\section{Response to the Concerns Expressed About the Review of Butcher et al. (2008)}

1. After receiving the note from the first author of the eventual rebuttal (Ben Porath et al. 2009), with its concerns about the Butcher et al. paper, the obvious decision to make was to review further the article in question. As indicated in the excerpts from the emails sent to the new reviewers, they were asked to review the entire article, not just the section with the anonymous excerpts of the letters [and I even checked with them on this if they indicated their acceptance of all but the letters component]. Therefore, in the end, four psychologists accepted this paper in its entirety, with two dissenting about inclusion of anonymous excerpts of the letters at issue.

It is fair to say that the perspective of the reviewers was that this article is one that is part of an ongoing debate, and there would be responses. The editorial rules in such cases are different, and the rebuttal-counter rebuttal format is the best way of dealing with them, so that the reader can decide. Both this article and the rebuttal were examined from the policy of letting the authors put their best case forward from a scientific perspective and to let the reader decide on the merits of the case presented. Therefore, the first article in the series was accepted within the limits that it is an article of the type meriting debate, rebuttal, and letting the reader decide, as per the editorial policy described in Young (2008a). The same policy was applied to the second article. The two sets of authors have continued their exchange, and a counter rebuttal appears in this issue. We look forward to a rebuttal of the counter rebuttal.

Moreover, we look forward to reader response in notes sent to the journal, which will be vetted for publication, as well as invited experts commenting on the series of articles. In our field, it is best to let ongoing debates continue, so that the science that underlies each article is scrutinized, in a careful manner, by psychologists, attorneys, triers of fact (judges, juries), and venues related to court.

Indeed, we look forward to publishing many debates of the type we are discussing, all from the sound scientific view. When disagreements arise, and there will be many, we look forward to sound research and reasoning, with responses that are impartial and respectful, even if there are disagreements.

The comment about the lack of editorial note preceding the article at issue is a fair one. Therefore, the journal has 
adopted the policy that for articles requiring such disclaimers in future issues of the journal, an appropriate editorial note will be included.

Looking back, I accept all responsibility for any errors in the editing of this informative series of articles. What is important is that the journal and I learn from what has transpired. This being said, I am but one member of a team, but in the present case, the team did not make the decisions being discussed. I take full responsibility.

2. Note that I did try to have the excerpts in question removed from the Butcher et al. article. I indicated to the authors that the excerpts did not especially deal with the scientific arguments being made, and the rest of the article could stand without them. The authors had agreed to remove the excerpts in order to accommodate to concerns expressed, and both they and I had agreed that in no way does this reflect any admission of wrong-doing. However, it proved impossible in the production department of the journal to revise article despite the authors agreeing to remove the excerpts. Being a new editor of a new journal, I was unaware that online versions are not drafts but are final versions even though hard copy production may be months away.

The reader should note that this issue detracts from the critical one of evaluating the scientific basis for the opinions offered in the two articles. Some might endorse the fact that only anonymous excerpts were published, and the confidentiality of the review process has remained intact.
Note that the authors of the rebuttal had also agreed to alter their original description of the inclusion of excerpted letters from their article, again at my request, in particular. In the end, I complimented both sets of authors for the flexibility that they had shown, despite their disagreements.

Acknowledgment Many thanks to Andrew Kane for helpful comments on the text. The author's work has been supported by course leaves granted by both Glendon College and York University and editorial grants from Springer Science + Business Media. In terms of possible conflicts of interest, the author has obtained most of his attorney referrals and psycholegal referrals from plaintiff rather than defense attorneys and assessment companies.

\section{References}

Ben-Porath, Y. S., Greve, K. W., Bianchini. K. J., \& Kaufmann, P. M. (2009). The MMPI-2 Symptom Validity Scale (FBS) is an empirically-validated measure of over-reporting in personal injury litigants and claimants: reply to Butcher et al. (2008). Psychological Injury and Law, 2(2), 62-85.

Butcher, J. N., Gass, C. S., Cumella, E., Kally, Z., \& Williams, C. L. (2008). Potential for bias in MMPI-2 assessments using the Fake Bad Scale (FBS). Psychological Injury and Law, 1(3), 191-209.

Young, G. (2008a). Psychological injury and law: Editorial introducing a journal and an association. Psychological Injury and Law, $1(1), 1-6$.

Young, G. (2008b). Editorial on PIL's First Year: Growing pains and growing prospects. Psychological Injury and Law, 1(4), 213.

Young, G. (2009). Psychological Injury and Law: Editorial note. Psychological Injury and Law, 2 (1), 61. 